\title{
Impact of Number of Security Analysts in Liquidity of Brazilian Stocks
}

\author{
Liliam Sanchez Carrete ${ }^{1}$, Vitor Corona ${ }^{1}$, Rosana Tavares ${ }^{1}$ \\ ${ }^{1}$ Department of Business Administration, FEA USP, Brazil \\ Correspondence: Liliam Sanchez Carrete, Department of Business Administration, FEA USP, Brazil. E-mail: \\ lscarrete@gmail.com
}

Received: September 14, 2016

Accepted: September 26, $2016 \quad$ Online Published: October 3, 2016

doi:10.5539/ibr.v9n11p105

URL: http://dx.doi.org/10.5539/ibr.v9n11p105

\begin{abstract}
This study investigates impacts of sell-side analysts in the liquidity of firm's shares of Brazilian Capital Markets. Liquidity hypothesis studied by Brennan and Subrahmanyan (1995), Brennan and Tamarowski (2000), Amihud and Mendelson (1986, 2000) and Amihud et al. (1997) defines that an increase in the number of analysts covering a particular stock increases its liquidity causing a positive impact on the stocks prices. This work investigates empirically whether increasing number of securities analysts impacts stock market liquidity, as observed in the American market by Brennan and Tamarowski (2000), using a sample of 179 listed stocks in the Brazilian stock exchange, BM\&FBovespa. This work determines liquidity-measuring firm's Lambda dollar derived by Kyle (1985) and then applying cross section regression of Lambda dollar as dependent variable and number of analysts as independent variable. Results indicate that stock market liquidity increased with number of securities stock analysts in favor of liquidity hypothesis.
\end{abstract}

Keywords: sell-side security analyst, stock liquidity, recommendation report, information asymmetry, trading volume

\section{Introduction}

Sell-side analysts hold a privileged position in capital markets compared to average investors. Such position is due to its close relationship with investor relations departments in order to access the most update and relevant information to develop buy and sell recommendation reports. This article has as main objective investigate the impact of sell-side security analysts in the liquidity of stocks listed in the Brazilian stock market. The relevance of this study is justified by Capital Market Efficiency Theory. Fama (1970) classified market efficiency in three different forms: weak, semi strong and strong form efficiency; each of them specifying the exactly type of information reflected in asset prices. If market is efficient in the strong form, no investor can earn excess returns using any information, whether publicly available or not, and sell-side securities analysts' recommendation reports should not have impact on stocks negotiation. In other words if all information, without exception, are already available and reflected in the stock price and that any and all deviation from the fair price is random not presenting any pattern which offers abnormal returns to investors, then sell-side analysts do not play a significant role in the capital markets.

Sell-side analysts' goal is identify stocks to recommend investors either to buy when market price is below its fair price or to sell when market price is higher. If investors accept analyst recommendations, they believe current market prices do not incorporate all information. Several studies have rejected market efficiency hypothesis. DeBondt and Thaler (1985) and Chopra, Lakonishok and Ritter (1992) concluded that stocks that present poor performance during a given period (five years in the study) tend to get strong performance in the following period, while stocks that performed better in the previous period will be likely to present a weak performance in the subsequent period.

Faced with the possibility of inefficiency presence in the capital market, security analysts are responsible to collect, interpret and analyze public information, in order to develop recommendation reports for their customers, indicating the purchasing, holding, or selling a particular stock. Ivkovic and Jegadeesch (2004) defines that sell-side analysts present two skills: analyze the publicly available and relevant information interpreting its long-term implications as well as investigate information not yet publicly available to investors and process and structure that information in order to provide their recommendation to investors. Studying the impact (positive 
externalities) that these analysts have in the capital markets provide potential evidences of inefficiency presence that could be minimized by securities analysts, speeding disseminating information among investors.

Some researchers have studied the consequences that analysts may have in the stocks return. Irvine (2003) showed that initiation reports (first report that an analyst issues about a particular stock) generate abnormal return higher than revision reports (post-initiation coverage report) in the US market. He explained that higher abnormal return is due to primarily an increase in firm's share liquidity, which occurs when new sell-side analysts start firm coverage. This concept is intrinsically linked to Brennan and Subrahmanyan (1995) and Brennan and Tamarowski (2000) findings. The latter defines that there is a clear chain of causality between (a) number of analysts who follow a firm and the liquidity of that's firm's shares and (b) liquidity of a firm's shares and the market's required return and as a consequence the stock price. They show that the increase in liquidity when there are a higher number of security analysts is due mainly to the decreased market information asymmetry as a whole.

Bushan (1989) investigates firm's characteristics that can influence security analyst's decision to follow them, which impose a closer relationship with corporate investor relations department, which in turn reduce the cost of information to analysts that would also increase analyst coverage. Analysts have, as their main role, to inform the market agents (reducing the information asymmetry) causing, according to Brennan and Subrahmanyan (1995), the decrease of the required capital cost for a particular stock, culminating therefore with a rise in the stock price. In this way, it is possible to see the correlation between number of analysts, information asymmetry, liquidity and return, corroborating the findings set out by Irvine (2003).

Therefore investigating the impact of analyst coverage in liquidity enables understanding the continuity of this cycle with the association between number of analysts and liquidity its consequence of a decrease on shareholders required capital return and increase of asset prices.

The study comprises an innovation in financial literature because it investigates impacts of sell-side analysts in the liquidity of firm's shares of the Brazilian Capital Markets. Therefore, the objective of this study is investigate empirically whether the increased number of securities analysts impacts stock market liquidity, as observed in the American market by Brennan and Tamarowski (2000). This work will determine liquidity-measuring firm's Lambda dollar derived by Kyle (1985) as a liquidity measure and then applying cross section regression of Lambda dollar as dependent variable and number of analysts as independent variable.

The remainder of this work proceeds as follows: section 2 reviews the market efficiency theory and liquidity hypothesis; section 3 provides a description of the data and empirical methodology and lays out the specific predictions of the model; section 4 presents the research accomplishment and sections 5 and 6 present the results and final considerations.

\section{Theoretical Reference}

\subsection{Market Efficiency - Empirical Evidence}

The market efficiency concept emerged by Roberts (1967) and enhanced by Fama (1970 and 1991) states that in an efficient market an asset prices are good estimates of their intrinsic value at any point in time. Bodie, Kane and Marcus (2008) defines that the efficient market hypothesis is the idea that all the information, without exception, are included in the securities prices. Jensen (1978) points out that in an efficient market no investor would have chance of obtaining economic profit with the available information.

One of the main anomalies in the capital market is called "January effect", which is the consistently positive return compared to other months. One of the reasons refers to investors' position adjustment from previous year closing. Banz (1981) showed that the average annual US market return (NYSE) between 1926 and 2006 was higher in small business portfolios, reaching a difference of $8.86 \%$ above big companies' portfolio. Gibbons and Hess (1981) identified the weekend effect, signaling that the average returns are lower on Mondays due to the incorporation of the bad news disclosed throughout the weekend. Basu (1977) showed that companies with lower index price/earnings $(\mathrm{P} / \mathrm{E})$ have higher returns than companies with higher P/E. This anomaly, related to the semi-strong hypothesis, is known as P/E effect.

According to Fama and French (1992) value stocks (high book value over market value), get higher returns than growth stocks (low book value over market value), even controlling by the risk. Damodaran (2002) interpret it as an anomaly called effect price/asset value (P/AV), in which companies with low P/AV have higher returns than companies with higher P/AV.

Despite these irregularities, market behavior related to those systematic factors can be understood as inefficiencies. There are evidences of asset managers who are professionals to explore those inefficiencies that 
have difficulties of beat the market and generate abnormal returns. Given this empirical contradiction the presence of security analysts is justified due to their ability of incorporating all available information to their valuation modeling to calculate the stock's fair value.

Brennan and Tamarowski (2000) states that there are reasons to suspect that prices might not conform to the predictions of the idealized efficient market theory because the complexity of firms with strategies, plans, commitments, personal policies, competitive threats, managerial succession problems, patents, research programs. Only a technical and financial expertise is required to understand and incorporate relevant information to determine assets intrinsic value.

Securities analysts are specialists that interpret and project information such as corporate financial statements, economic, sector environment data, and private information to identify stocks that priced below or above their intrinsic values. This positive relation between analyst coverage and trading can improve market efficiency because security analyst reports speeds incorporating new information to stock's market prices.

Ivkovic and Jegadeesh (2004) defines that security analysts play an important role in collecting and processing information about firms providing investors earnings forecasts and stock recommendations due to their ability of interpret and process long-term implications of financial data reported by firms and a wide variety of information.

More recently, Chen, Cheng and Lo (2010) propose that the usefulness of analyst research potentially derives from two sources: the discovery of a private information and interpretation of public information. Using stock market reaction, they found that information discovery dominates in the week before earning-announcement date by firms and interpretation dominates the week after firms announce their earnings. They show an overall pre-emption effect of analyst revisions relative to earnings announcement, which means information discovery role, is more important.

Finally, Livnat and Zhang (2012) based on previous researches, assume that securities analysts play important role in the capital market, supplying information and data interpretation. These authors examine the market reaction to forecast revisions promptly issued after corporate disclosures versus those that are not. Their results indicate that investors react more strongly to prompt revisions immediately after earnings announcements, which can be interpreted as investors attaching greater value to interpretation role than discovery role, contrasting to Chen, Cheng and Lo (2010).

The possible reason for several brokerage firms invest in securities analysts' teams from different sectors is that they believe they may generate greater returns for their customers and, consequently, will increase the securities trading volume, which in turn would generate more revenue for the brokerage firm. Bhushan (1989) studied how securities analysts decide to follow firms and its evidences related to recommendation reports demand. $\mathrm{He}$ investigated if firms' characteristics could influence the decision and the most relevant firms' characteristics that affect analyst coverage decision are number of insider and institutional holdings, number of lines of business and size of companies.

If firm's characteristics can influence the decision of analysts to follow them, which impose a closer relationship with corporate investor relations department and causing a decrease in the cost of information to analysts that would also increase analyst coverage. If an increase in the number of analysts following a firm affects liquidity, there is evidence of market efficiency improvement.

\subsection{Abnormal Return as a Result of Analysts' Reports}

Irvine (2003) studied the abnormal return generated by the initiation report (first report that a particular security analyst issues about a firm's stock) and the revision report (post-initiation coverage report). He concluded that the initiation report presents an abnormal return higher than the return presented by the revision report, mainly due to the increased liquidity generated by the initiation report (increasing number of analysts). Irvine (2003) is a relevant study due to the following reasons: first, it corroborates the presence of the market inefficiency and second, associates the increase in liquidity with the increased number of securities analysts.

Irvine (2003) uses a sample of 2,128 reports of the NYSE from the second and third quarter of 1995, being 1,064 of initiation reports and 1,064 of revision reports. Reports that indicated strong buy were 690 (32\%), 660 (31\%) had the buy recommendation, 705 (33\%) received hold recommendation and 73 (3\%) sell recommendation. Among the main findings, the author identified there are abnormal return generated by recommendation reports, the initiation reports $(0.75 \%)$ were $1.02 \%$ higher than the abnormal returns generated by coverage revision reports $(-0.26 \%)$. 
Ivkovic and Jegadeesh (2004) examines stock price reactions to stock recommendations released at various points in time relative to earnings announcements from data on sell-side analysts' earnings forecasts for the period from January 1990 to March 2002 from I/B/E/S database. Results indicate that stock price reactions are weakest in the weeks following earning-announcement date and strongest in the week prior to earning-announcement date for upgrades. On the other hand, stock price reactions are stronger for downgrade some weeks prior the earning-announcement date that weakens in the last two weeks before earning-announcement date. One of the possible reasons for this asymmetry is that analysts have early access to positive news prior to the earnings announcements from insiders and perhaps managers are more reluctant to provide guidance to analysts when they have bad news than when they have good news.

One of the possible explanations to those evidences is related to the liquidity hypothesis such as an increase in the number of analysts of a particular stock increases its liquidity causing a positive impact on the stocks prices. This hypothesis was developed by Brennan and Subrahmanyan (1995), Brennan and Tamarowski (2000), Amihud and Mendelson (1986, 2000) and Amihud et al. (1997).

Brennan and Subrahmanyam (1995) conclude that the increase in the liquidity, whenever there is an increase in the number of securities analysts, is because there is a reduction in the information asymmetry. According to Amihud and Mendelson (1986, 2000), Amihud et al. (1997) and Brennan and Subrahmanyam (1995) the lower the information asymmetry, the lower the capital cost for a particular stock and as a consequence higher its price.

\subsection{Liquidity Hypothesis}

Brennan e Tamarowski (2000) investigates the effect of sell-side analysts' following on the liquidity of trading in the firm's shares by reducing informational asymmetry. This finding is consistent with other researches about the effectiveness of analysts in speeding the dissemination of information improving market efficiency. Understanding factors that influence liquidity is important because helps understanding its effect on the stock prices. Those authors believe that increases in liquidity reduce investors' required rates of return and so increase stock prices. In other words stock prices increase due to a reduction in the cost of capital.

Sharpe (1999) defines liquidity as the ability to convert stocks, bonds or any other asset in cash, for a price similar to the latest practiced, if no new information has arisen an important concept when studying liquidity in finance is to understand bid and ask spread. This concept refers to the difference in the price of the offer to buy (bid) and the price of the offer to sell (ask). Several studies have shown that assets with greater spread are usually associated to lower liquidity and small spreads tend to be related to assets with high liquidity.

According to Brennan and Tamarowski (2000), many researchers choose the bid and ask spread as the measure for measuring the liquidity of a particular stock. However, as shown by the study of Petersen and Fialkowski (1994), investors pay on average only 52\% - 63\% of the offered spread. In addition, the correlation found between the effective and the offered spread is only 0.10 .

For these reasons, Kyle (1985) proposed a new way of measuring a stock liquidity in the market, through the marginal impact of trading on the stock price. This liquidity measure has become widely used in other studies. It corresponds to the line regression slope to the time-series behavior of prices with trading volume of shares - the straight-line coefficient became known as Kyle lambda, $\lambda$ :

$$
P_{t}-P_{t-1}= \pm \Delta+\lambda q_{t}+\varepsilon_{t}
$$

$P_{t}=$ closing market price on day $\mathrm{t}$;

$P_{t-1}=$ closing market price previous day;

$\pm \Delta=$ coefficient to be estimated. It is understood as the amount necessary to offset the market maker for his costs in the transaction being the signal dependent on whether it is a purchase or sale operation;

$\lambda=$ Kyle Lambda that measures the impact on the price given a trading volume;

$q_{t}=$ quantity of trading volume of shares on day $\mathrm{t}$ and

$\varepsilon=$ error term on day t.

Figure 1 represents equation 1 in two straight lines where $\lambda$ is the line inclination for both a liquid stock and an illiquid stock. The liquid stock (line 1) has a lower inclination therefore a smaller $\lambda$, since for a given trading volume, the lower the price variation. On the other hand, the illiquid stock (line 2) shows greater variation in the price for a given trading volume, and therefore a greater $\lambda$. Lambda measures the marginal impact of a trade of the price of shares, explained by the fact that the price concession for a given size trade is largest for an illiquid stock than for a liquid one. 


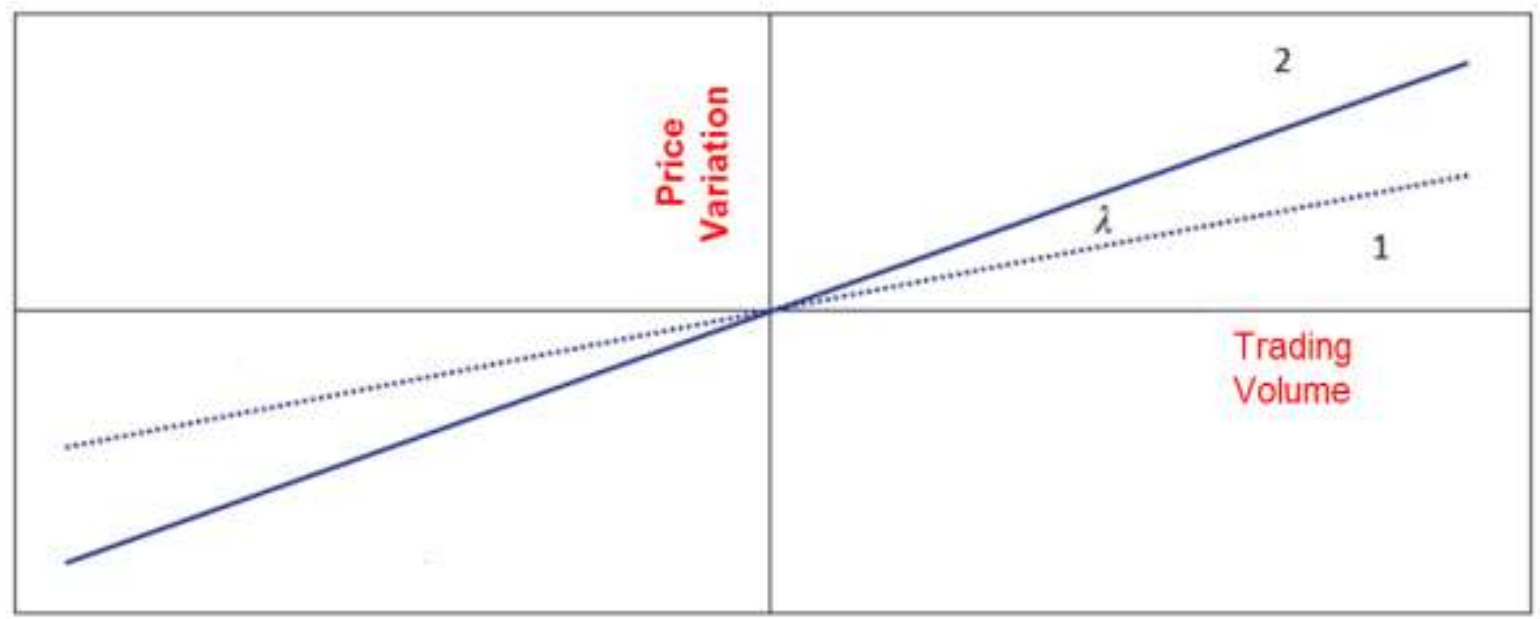

Figure 1. $\lambda$ as measure of liquidity (Brennan e Tamarowski, 2000)

Kyle (1985) argued in his study that the illiquidity is due to the information asymmetry degree on the stock intrinsic value (which would generate a greater change in price, as represented by line 2 in Fig. (1). He concluded that because of the information asymmetry, investors who have better information on certain stock, would create a transaction cost over the other market agents, reducing the liquidity of this stock, which is often called of adverse selection.

Investors who are less informed add a greater loss cost for the stock about which they do not have complete information. Thus, they are not willing to pay what the seller asks, and therefore, there is no transaction, reducing the stock liquidity. Consequently, in a market with higher information asymmetry, liquidity tends to be smaller, resulting in a higher $\lambda$ to the stock. In that context, securities market analysts present their relevance, since they help to increase informational level of market agents, reducing adverse selection and the market asymmetry, which tends to increase stock liquidity.

Aiming at measuring the impact per dollar by the negotiation size, it was created the measure $\lambda$ dollar obtained by the relation of the $\lambda$ by the average stock price, according to the equation 2 :

$$
\$ \lambda=\frac{\lambda}{P}
$$

Where:

$\$ \lambda=$ Lambda dollar

$\lambda=$ Lambda (it measures the impact on the price, given a trading volume of shares)

$\mathrm{P}=$ Average Stock Price

The hypothesis of liquidity increased, measured by the correlation between the increase in the number of analysts covering the stock and its respective liquidity was tested by Brennan and Tamarowski (2000) in their studies for the American market. The test comprised the application of the cross section logarithm regression of Lambda dollar $\$ \lambda$ (liquidity) on number of sell-side analysts, average daily market value average daily trading volume in shares and average daily stock price as per the following cross section ordinary least squares regression equation:

$$
\ln \left(\$ \lambda_{i}\right)=\beta_{0}+\beta_{1} A_{i}+\beta_{2} Q_{i}+\beta_{3} P_{i}+\beta_{4} \sigma_{i}^{2}+\varepsilon_{i}
$$

Where:

$\operatorname{Ln}\left(\$ \lambda_{i}\right)=$ logarithm of lambda dollar of firm i;

$A_{i}=$ logarithm of the number of analysts +1 of firm i;

$Q_{i}=$ logarithm of the average daily trading volume in shares of firm i;

$P_{i}=$ logarithm of the average daily price of firm i;

$\sigma_{i}^{2}=\log$ arithm of the average daily return variance of firm $i$ and

$\varepsilon_{i}=$ error term of firm i.

Main results of Brennan and Tamarowski (2000) that covers 1,441 shares of the NYSE in 1988 confirms a strong 
and negative relationship between the number of sell-side analysts covering the firm and $\$ \lambda$ due to the coefficient $\log (1+$ number of analysts) of -0.169 , statistically significant $(t-s t a t i s t i c=3.13)$, in accordance with the liquidity hypothesis. Moreover riskier stocks, which are measured by daily return variance, are less liquid due to its positive and statistically significance coefficient of $0,638(\mathrm{t}$-statistic $=18,40)$ and that stocks with lower prices are also less liquid (coefficient $=0,275$ and t-statistic $=6,42$ ).

In order to get stronger evidences of the impact of sell-side analysts covering a firm, Brennan and Tamarowski (2000) applied another test by regressing trading volume on the logarithm of (1+ number of investment analysts following the firm) and other variables: number of sell-side analysts, daily average price and market capitalization. Main results indicate that number of analysts covering a particular stock has an important impact on the average trading volume (coefficient $=0,897$ and $t$-statistic $=13,31$ ). This result is quite consistent with the fact that the brokers employ analysts so that they can generate more trading volume and thus generate more revenue, so that the costs are paid. It is also consistent with their role of sell-side analysts as information disseminators and that their reports reduce the information asymmetry among investors. Thus, Brennan and Tamarowski (2000) concluded that in the US market, for the sample adopted, it is possible to say, in general terms, that the increase in the number of analysts, causes the increase also in the stocks liquidity.

The same research obtained a difference of 662 basis points of cost of capital between the most and the least liquid stock quintiles, so the higher the liquidity (lower $\lambda$ )) the lower the required return. The same way higher, the required return and cost of equity capital less. Similar conclusion was found by Botosan (1997) which results indicates that companies that are covered by more analysts have around $10 \%$ reduction in its cost of equity capital compared to those that have low quantity of analyst covering them.

\section{Methods}

This research hypothesis comprises identify the existence of a negative relation between sell-side analyst coverage and liquidity in order to understand the function of security analyst in the Brazilian capital market efficiency. Previous researches indicate that there is an increase in the liquidity, whenever there is an increase in the number of securities analysts due to a reduction in the information asymmetry.

To test this liquidity hypothesis in the Brazilian stock market, this research is going to implement Brennan and Tomarowski (2000)'s methodology for Brazilian companies listed at BMF\&BOVESPA. This study collected data from Bloomberg data base biggest companies as per their market capitalization value of Brazilian stock market with available information as of December 302013.

The first step is calculate Kyle Lambda through ordinary least squares linear regression using daily returns to each the 179 firm's stock of the sample of 2013 daily closing prices as per equation (1).

The second step comprises calculating the Lambda Brazilian Reais, $R \$ \lambda$, as per equation (5) modified from dollars Eq. (2) to Brazilian Reais to 2013:

$$
R \$ \lambda=\frac{\lambda}{P}
$$

Where:

$R \$ \lambda=$ Lambda reais;

$\lambda=$ Kyle Lambda;

$\mathrm{P}=$ Average Stock Price of 2013 .

The third step consists of the logarithm regression (equation 3) between the calculated $R \$ \lambda$, and number of analysts covering the stock, average trading volume, average stock price and variance of daily trading amount of stocks.

Finally, the last step is implement the cross section ordinary least squares regression to test if the number of analysts covering a firm influences its trading volume. The dependent variable is the average daily trading volume in shares against number of analysts to confirm the impact of sell- side analysts on trading volume.

\section{Results}

\subsection{Data}

The sample used in this study was collected from Bloomberg database and consists of 179 larger companies (measured by market value) with liquidity every working day from January 1, 2013 to December 31, 2013 listed on BM\&FBovespa. The sample comprises approximately $40 \%$ of the listed companies and $98 \%$ of participation in total market value of the BM\&FBovespa. Table 1 presents descriptive analysis of the sample of 179. 
Table 1. Descriptive statistics of the sample

\begin{tabular}{llll}
\hline & Trading Volume(in stocks) & Number of analysts & Market value(R\$ million) \\
\hline Arithmetic Mean & 2.268 .828 & 10 & 9.164 \\
Median & 597.850 & 11 & 699 \\
Minimum & 1 & 0 & 19 \\
Maximum & 187.387 .700 & 22 & 263.955 \\
\hline
\end{tabular}

The table presents the average daily trading volume of shares in 2013, the number of analysts and the average daily market value of all companies from the sample. The daily trading volume has very discrepant values measured the maximum and minimum quantity of daily trading volume of shares: the largest movement of a company in one day in 2013 was 187,387,700 shares, while the smallest amount was of one. Regarding the quantity of analysts covering firms of the sample, it is observed that there is a large concentration of analysts in the large companies and only 17 companies that are not covered by sell-side equity analysts. The average is 10 analysts per company.

\section{$4.2 \lambda$ and $R \$ \lambda$ of the Sample}

To calculate the $\lambda \mathrm{s}$ of the companies it was obtained the daily closing price of the stocks and the respective daily trading volume of each of the stocks in the period between January 02, 2013 and December 30, 2013. Having both, the module price variation and the trading volume in number of stocks for each of the trading session days of 2013, it was possible to calculate the slope of each of the 179 regressions and thus calculate the $\lambda$ and $R \$ \lambda$ for all companies in the sample. Table 2 presents the descriptive statistics of these two variables:

Table 2. Descriptive statistics of the $\lambda$ and of the $R \$ \lambda$

\begin{tabular}{lll}
\hline & Lambda $(\lambda)$ & Lambda BrReal $(\mathrm{R} \$ \lambda)$ \\
\hline Arithmetic Mean & $7,42 \mathrm{E}-05$ & $5,65 \mathrm{E}-07$ \\
Median & $1,00 \mathrm{E}-07$ & $6,58 \mathrm{E}-09$ \\
Minimum & $2,13 \mathrm{E}-10$ & $9,43 \mathrm{E}-11$ \\
Maximum & $8,57 \mathrm{E}-03$ & $5,98 \mathrm{E}-05$ \\
\hline
\end{tabular}

The lower the $\lambda$ and the $R \$ \lambda$, the greater the security liquidity, and thus the greater the $\lambda$ and the $R \$ \lambda$, the lower is the stock liquidity. The arithmetic mean is 7.38E-05 and 5.26E-07 for the $\lambda$ and the $R \$ \lambda$ respectively.

In order to test the hypothesis of this article whether the increase of the number of analysts covering a firm increases the stock liquidity the cross section regression of Lambda Brazilian Reais, $R \$ \lambda$, equation (6) was implemented. Additionally, the regression of trading volume of shares on number of analysts' equation (4) was also implemented. It is expected a negative and statistically significant coefficient of number of analysts on equation (6) and a positive and statistically significant coefficient of the same variable on equation (4).

Table 3 presents correlation matrix of variables used in regressions and there are relevant results to be evidenced. First, correlation between trading volume, $\mathrm{Q}$, and number of analysts, A, is positively high $(0,81)$ which can be understood as number of analysts affecting trading volume of shares. Second, correlation between Lambda Brazilian Reais and Trading Volume is negatively high $(-0,81)$ indicating that liquidity is highly correlated with trading volume. And third, correlation between number of analysts is negatively correlated $(-0,62)$ which signalizes that number of analysis is positively correlated with liquidity as expected.

Table 3. Correlation Matrix

\begin{tabular}{|c|c|c|c|c|c|c|}
\hline & A & $\mathbf{Q}$ & $\mathbf{P}$ & $\sigma_{i}{ }^{2}$ & M & $\operatorname{Ln}(R \$ \lambda)$ \\
\hline A & 1,00 & 0,81 & $-0,07$ & $-0,20$ & 0,44 & $-0,62$ \\
\hline $\mathbf{Q}$ & 0,81 & 1,00 & $-0,29$ & $-0,20$ & 0,44 & $-0,81$ \\
\hline$P$ & $-0,07$ & $-0,29$ & 1,00 & $-0,39$ & 0,06 & 0,22 \\
\hline$\sigma_{i}^{2}$ & $-0,20$ & $-0,20$ & $-0,39$ & 1,00 & $-0,16$ & 0,35 \\
\hline M & 0,44 & 0,44 & 0,06 & $-0,16$ & 1,00 & $-0,31$ \\
\hline $\operatorname{Ln}(\operatorname{R} \$ \lambda)$ & $-0,62$ & $-0,81$ & 0,22 & 0,35 & $-0,31$ & 1,00 \\
\hline
\end{tabular}

Table 4 presents regression results equations (6) and (4). When analyzing the coefficient signals, it is observed that the number of analysts have a negative signal, indicating that this variable moves in the opposite direction of the dependent variable $R \$ \lambda$, showing that in case of increase (decrease) in the number of analysts, the $R \$ \lambda$ would decrease (would increase). Since $R \$ \lambda$ is the opposite of liquidity results are consistent with what was expected: number of analysts following a firm affects stocks liquidity. That coefficient also presents statistical significance in equations where trading volume of shares was not included as explanatory variable, regressions (1), (2) and 
(3). In Regressions (4) and (5) coefficient of number of analysts are positive and without statistical significance. Squared R of regressions (1), (2) and (3) are 0,39; 0,43 and 0,52 respectively lower than regressions (4) and (5) squared $\mathrm{R}(0,70)$.

The coefficients of variable price are statistically significant signalizing that stocks with smaller prices affect liquidity positively consistent with Brennan and Tamarowski (2000). Regarding variable market value, neither of them presented statistical significance.

Table 4. Regression Results

\begin{tabular}{|c|c|c|c|c|c|c|c|c|c|}
\hline $\begin{array}{l}\text { Explanatory } \\
\text { Variables }\end{array}$ & $\operatorname{Ln}(R \$ \lambda)$ & $\operatorname{Ln}(R \$ \lambda)$ & $\operatorname{Ln}(R \$ \lambda)$ & $\operatorname{Ln}(R \$ \lambda)$ & $\operatorname{Ln}(R \$ \lambda)$ & $\boldsymbol{Q}$ & $\boldsymbol{Q}$ & $\boldsymbol{Q}$ & $\boldsymbol{Q}$ \\
\hline & (1) & (2) & (3) & (4) & (5) & (6) & (7) & & (9) \\
\hline Constant & $-15,83$ & $-11,18$ & $-10,14$ & $-5,55$ & $-5,81$ & 8,70 & $-0,50$ & 1,30 & 0,49 \\
\hline$t$-Statistic & $-55,17$ & $-9,31$ & $-9,09$ & $-5,51$ & $-5,55$ & 18,34 & $-0,62$ & 1,52 & 0,55 \\
\hline $\bar{A}$ & $-1,30$ & $-1,21$ & $-1,10$ & 0,16 & 0,14 & 1,97 & 1,22 & 1,26 & 0,17 \\
\hline t-Statistic & $-10,61$ & $-10,00$ & $-9,92$ & 1,00 & 0,89 & 18,34 & 11,77 & 12,84 & 11,47 \\
\hline $\mathrm{Q}$ & & & & $-0,68$ & $-0,69$ & & & & \\
\hline t-Statistic & & & & $-9,93$ & $-9,90$ & & & & \\
\hline$P$ & & & 0,63 & 0,18 & 0,17 & & & $-0,33$ & $-0,36$ \\
\hline t-Statistic & & & 5,88 & 1,88 & 1,69 & & & $-4,67$ & $-5,06$ \\
\hline$\overline{\sigma_{i}^{2}}$ & & 0,62 & 1,00 & 0,65 & 0,65 & & & & \\
\hline$t$-Statistic & & 3,98 & 6,39 & 5,00 & 4,98 & & & & \\
\hline$M$ & & & & & 0,06 & & & & 0,15 \\
\hline$t$-Statistic & & & & & 0,91 & & & & 2,79 \\
\hline $\operatorname{Ln}(R \$ \lambda)$ & & & & & & & $-0,58$ & $-0,53$ & $-0,52$ \\
\hline$t$-Statistic & & & & & & & $-11,75$ & $-10,98$ & $-10,98$ \\
\hline $\mathbf{R}^{2}$ & 0,39 & 0,43 & 0,52 & 0,70 & 0,70 & 0,65 & 0,81 & 0,83 & 0,84 \\
\hline
\end{tabular}

When analyzing regressions which trading volume of shares is the dependent variable, $\mathrm{Q}$, all coefficients of number of analysts, A, are positive and statistically significant which can be interpreted that when there is an increase in the number of analysts, there is also an increase in average trading volume. Finally, it is worth highlighting the high $\mathrm{R}^{2}$ presented, which shows a high degree of the model explanation through the proposed variables.

\section{Discussion}

Analyzing results presented on (Table 4), it can be inferred that there is a strong (statistically significant) and negative relationship between number of securities analysts and Lambda Brazilian Reais, $R \$ \lambda$, (regressions 1, 2 and 3). This result suggests that analysts positively increase the stock liquidity, since the increase in the number of analysts causes a decrease in the $R \$ \lambda$, which, as previously explained, indicates a liquidity increase. This conclusion is consistent with those obtained in Brennan and Tamarowski (2000).

Number of securities analysts influences the average trading volume as per equations (6), (7), (8) and (9) since coefficients of variable number of analysts are positive and statistically significant. Therefore, trading volume of shares can be interpreted as a liquidity measure.

Regressions (3) to (5) and (6) to (9) show that the higher the stock price, the lower tends to be the trading volume of shares, which is also widely accepted in the reality of markets, including in Brazil. Additionally, regressions (2) to (5) results in positive coefficients of daily return variance statistically significant signaling that risk is negatively correlated with liquidity, consistent with Brennan and Tamarowski (2000).

As expected, correlation matrix presents that $\operatorname{Ln}(R \$ \lambda)$ is inversely associated to the average trading volume since a more liquid stocks (smaller $R \$ \lambda$ ) have a greater trading volume. Regressions coefficients are negative and statistically significant which enables interpreting that both variables can be used as liquidity measure. These results are consistent with those obtained in Brennan and Tamarowski (2000).

Therefore, the evidences from this sample of 179 companies listed on the BM\&FBovespa in 2013, are that the securities analysts increase the liquidity of the Brazilian market. Coefficients of number of analysts are negative in regressions (1), (2) and (3) and statistically significant, as well as, positive and statistically significant in regressions (6) to (9). There were two exceptions in regressions (4) and (5) when trading volume of shares in included as explanatory variable. In those regressions coefficient of number of analysts are not statistically significant. 
These results are consistent with the theory that the analysts, through their reports, help reduce the information asymmetry and thus it may positively influences the stock market liquidity, in the Brazilian case. There are two important consequences from the evidence that sell-side securities analysts can increase stocks liquidity: the compensation for the increase in revenues for the brokerage firms for the maintenance of investment analysts area and the relevance of firms investor relations area providing relevant information to sell-side analysts.

When assessing relation between number of analysts and trading volume, it confirms the expectations, since the brokerage firms would only hire a team of analysts, which has its due cost, if they had the compensation in the form of higher volumes of generated business, which, for the brokerage firm, would generate higher revenue.

According to Brennan and Subrahmanyam (1995), more liquid stocks usually present a lower capital cost than less liquid stocks. This directly influences the respective stocks price, as a lower capital cost causes an increase in the stock price. In this context, as also shown in the study of Brennan and Subrahmanyam (1995), a company that has a well-structured area of investors relations, causes the security analysts to be better equipped with information and thus make their customers better informed ones. Thereby the information asymmetry decreases among investors, which could bring a liquidity increase to the stock and thus a stock price increase since the respective capital cost tends to decrease as the stock liquidity increases. Thus, the area of investor relations presents an important role within the organization since if it is well structured, and consistently supplying the analyst with information, it may have a positive impact on the company stock price.

\section{Final Considerations}

The main objective of this work comprises investigating impact of number of sell-side analysts on liquidity of stocks listed in the Brazilian stock exchange. Efficient market theory justifies the relevance of this study once it states that in its strong form, no investor can earn excess returns using any information, whether publicly available or not. Thus, sell-side securities analysts' recommendation reports should not have impact on stocks negotiation. Empirical evidence signalizes the validity of liquidity hypothesis that states an increase in number of analysts covering a particular stock helps disseminating information that will improve on average number of informed investors. Therefore, information asymmetry decreases which stimulates trading, influencing stock's liquidity.

Bushan (1989) investigates firm's characteristics that can influence security analyst's decision to follow them, which impose a closer relationship with corporate investor relations department, which in turn reduce the cost of information to analysts that would also increase analyst coverage. Results of Brennan and Tamarowski (2000) indicate that share liquidity increase when there is an increase in the number of analysts. Irvine (2003) presents evidences that investors who follow security analyst recommendations obtain abnormal return. Author explains this fact through the increased liquidity caused by the coverage initiation report. Due to this liquidity increase, there is a consequent reduction in the capital cost and an increase in the stock price.

This study implemented methodology of Brennan and Tamarowski (2000) using a sample of 179 stocks listed at BM\&FBovespa. Regressions with dependent variable is the liquidity measure Lambda Brazilian Reais, $R \$ \lambda$ the negative and statistical significance of coefficients of number of analysts are evidence in favor of liquidity hypothesis that the increase in the number of analysts increases the stock market liquidity (remembering that the lower the $R \$ \lambda$, the greater the liquidity of a particular stock). Regressions with dependent variable trading volume of shares, $Q$, as an alternative of liquidity measure results in strong signaling of the positive relationship of the number of analysts and the average trading volume. Therefore, results indicate that the increase in the number of securities stock analysts, indeed increased the stock market liquidity in favor of liquidity hypothesis.

This study did not investigate causality between analyst decision to follow a firm and liquidity. This limitation does not invalidate results because as evidenced by Bushan (1989) security analyst's coverage decision is related to ownership structure, firm size, return variability and lines of business what reinforces the expected causality effect consists of analyst decision to follow a firm and its market liquidity. Thus it emerge two relevant points. First, the association between analyst decision and liquidity may influence its relationship with investors' relations area that will: assure that securities analysts are always well informed and, being so, they are able to reduce market information asymmetry. Therefore, this study can also be a contribution for understanding the important role that the investor relations area has in the stock market. Second, maintenance of equity research areas by brokerage firms can be justified because analyst coverage increases trading volume, which generates higher broker revenues.

Finally, it is possible to implement subsequent studies to obtain additional evidences of cause and effect of analyst coverage decisions, information asymmetry and stock price response such as Brennan and Tamarowski (1995) discusses here just theoretically, not empirically. This study comprised a sample of 179 companies that represents $40 \%$ of the companies listed on the BM \& FBovespa, besides the fact that it studied only 2013. 


\section{References}

Amihud, Y., \& Mendelson, H. (1986). Asset pricing and the bid ask spread. Journal of Financial Economics, 17(2), 223-249. http://dx.doi.org/10.1016/0304-405X(86)90065-6

Amihud, Y., \& Mendelson, H. (2000). The liquidity route to a lower cost of capital. Journal of Applied Corporate Finance, 12(4), 8-25. http://dx.doi.org/10.1111/j.1745-6622.2000.tb00016.x

Amihud, Y., Mendelson, H., \& Lauterbach, B. (1997). Market microstructure and securities values: evidence from the Tel Aviv stock exchange. Journal of Financial Economics, 45(3), 365-390. http://dx.doi.org/10.1016/S0304-405X(97)00021-4

Banz, R. W. (1981). The relationship between return and market value of common stocks. Journal of Financial Economics, 9(1), 3-18. http://dx.doi.org/10.1016/0304-405X(81)90018-0

Basu, S. (1977). Investment performance of common stocks in relation to their price-earnings ratios: a test of efficient market hypothesis. Journal of Finance, 32(3), 663-682. http://dx.doi.org/10.1111/j.1540-6261.1977.tb01979.x

Bhushan, R. (1989). Firm characteristics and analyst following. Journal of Accounting \& Economics, 11(2-3), 255-274. http://dx.doi.org/10.1016/0165-4101(89)90008-6

Bodie, Z., Kane, A., \& Marcus, A. J. (2008). Investments. Fifth edition. McGraw-Hill Irwin.

Botosan, C. A. (1997). Disclosure level and the cost of equity capital. Accounting Review, 72(3), 323-349.

Brennan, M. J., \& Subrahmanyan, A. (1995). Investment analysis and price formation in securities markets. Journal of Financial Economics, 38(3), 361-381. http://dx.doi.org/10.1016/0304-405X(94)00811-E

Brennan, M. J., \& Tamarowski, C. (2000). Investor relations, liquidity and stock prices. Journal of Applied Corporate Finance, 12(4), 26-37. http://dx.doi.org/10.1111/j.1745-6622.2000.tb00017.x

Chen, X., Cheng, Q., \& Lo, K. (2010). On the relationship between analyst reports and corporate disclosures: exploring the roles of information discovery and interpretation. Journal of Accounting \& Economics, 49(3), 206-226. http://dx.doi.org/10.1016/j.jacceco.2009.12.004

Chopra, N., Lakonishok, J., \& Ritter, J. (1992). Measuring abnormal performance: do stocks overreact. Journal of Financial Economics, 31(2), 235-268. http://dx.doi.org/10.1016/0304-405X(92)90005-I

Damodaran, A. (2002). Avaliação de Investimentos: ferramentas e técnicas para determinação do valor de qualquer ativo. Rio de Janeiro: Qualitymark, $1^{\mathrm{a}}$. edição, 4a. reimpressão.

De Bondt, W. F. M., \& Thaler, R. (1985). Does the stock market overreact? The Journal of Finance, 40(3), 793-805. http://dx.doi.org/10.1111/j.1540-6261.1985.tb05004.x

Fama, E. F. (1970). Efficient capital markets: A review of theory and empirical work. The Journal of Finance, 25(2), 383-417. http://dx.doi.org/10.2307/2325486

Fama, E. F. (1991). Efficient capital markets II. The Journal of Finance, 46(5), 1575-1617. http://dx.doi.org/10.1111/j.1540-6261.1991.tb04636.x

Fama, E. F., \& French, K. R. (1992). The cross-section of expected stock returns. The Journal of Finance, 47(2), 427-465. http://dx.doi.org/10.1111/j.1540-6261.1992.tb04398.x

Fama, E. F., \& French, K. R. (1993). Common risk factors in the returns on stocks and bonds. The Journal of Financial Economics, 33(1), 3-56. http://dx.doi.org/10.1016/0304-405X(93)90023-5

Gibbons, M. R., \& Hess, P. (1981). Day of the week effects and asset returns. Journal of Business, 54(4), 579-596. http://dx.doi.org/10.1086/296147

Irvine, P. J. (2003). The incremental impact of analyst initiation of coverage. Journal of Corporate Finance, 9(4), 431-451. http://dx.doi.org/10.1016/S0929-1199(02)00053-6

Ivkovic, Z., \& Jegadeesh, N. (2004). The timing and value of forecast and recommendation revisions. Journal of Financial Economics, 73(3), 433-463. http://dx.doi.org/10.1016/j.jfineco.2004.03.002

Jensen, M. C. (1978). Some anomalous evidence regarding market efficiency. Journal of Financial Economics, 6(2-3), 95-101. http://dx.doi.org/10.1016/0304-405X(78)90025-9

Kyle, A. S. (1985). Continuous auctions and insider trading. Econometrica, 53(6), 1315-1335. http://dx.doi.org/10.2307/1913210 
Livnat, J., \& Zhang, Y. (2012). Information interpretation or information discovery: which role of analysts do investors value more? Review of Accounting Studies, 17(3), $612-641$. http://dx.doi.org/10.1007/s11142-012-9193-8

Petersen, M. A., \& Fialkowski, D. (1994). Posted versus effective spreads: good prices or bad quotes. Journal of Financial Economics, 35(3), 269-292. http://dx.doi.org/10.1016/0304-405X(94)90034-5

Roberts, H. (1967). Statistical versus clinical prediction in the stock market, University of Chicago.

Sharpe, S. A. (1999). Stock prices, expected returns, and inflation. Federal Reserve Board - Research \& Statistics. FEDS Working Paper, 99-2. http://dx.doi.org/10.2139/ssrn.155071

\section{Copyrights}

Copyright for this article is retained by the author(s), with first publication rights granted to the journal.

This is an open-access article distributed under the terms and conditions of the Creative Commons Attribution license (http://creativecommons.org/licenses/by/4.0/). 